\title{
Development of a Positive Displacement Micro-Hydro Turbine*
}

\author{
Dousith PHOMMACHANH ${ }^{* *}$, Junichi KUROKAWA***, \\ Young-Do $\mathrm{CHOI}^{* * *}$ and Noboru NAKAJIMA***
}

\begin{abstract}
The objective of this study is to develop an efficient turbine that can be used to extract micro hydropower potential of a water supply system. For the case of high head and critical low flow rate range of micro hydropower resources, it requires very low specific speed turbines which are lower than conventional impulse turbines' specific speed. For this purpose, we develop a new Positive Displacement Turbine (PDT). In order to reveal the performance characteristics of the new turbine, one conventional impulse turbine, which is used for automatic water faucet system, was tested for comparison. The test results show that the PDT was much more efficient than a conventional turbine and it can sustain high efficiency under the wide range of operating conditions. In addition, the efficiency of the PDT is much improved when reducing its side clearance. The pressure pulsations at the inlet and outlet of the PDT can be considerably minimized by using simple dampers.
\end{abstract}

Key Words: Turbomachine, Water Turbine, Positive Displacement Turbine, Water Supply System, Performance Improvement

\section{Introduction}

There are many available micro-hydropower resources surrounding us for extraction, such as rivers, municipal water supply systems of towns, drainage water from houses, irrigation canal and so on. The least expensive small hydropower systems are those that utilize the pipe systems ${ }^{(1)}$. These systems only require the placing of a turbine on the pipe and no major/no civil works are required. Recently, several types of turbines have been used for extracting the energy from micro hydropower resources $^{(2)-(4)}$. The selection of the best turbine for any particular hydro site depends on the site characteristics ${ }^{(4)}$, the dominant factors being the head and flow rate avail-

* Received 26th September, 2005 (No. 05-4168)

** Division of Systems Integration, Graduate School of Engineering, Yokohama National University, 79-5 Tokiwadai, Hodogaya-ku, Yokohama 240-8501, Japan.

E-mail: dousith@mach.me.ynu.ac.jp

*** Division of Systems Research, Faculty of Engineering, Yokohama National University, 79-5 Tokiwadai, Hodogaya-ku, Yokohama 240-8501, Japan.

E-mail: kuro@post.me.ynu.ac.jp; ydchoi@mach.me.ynu. ac.jp

**** Engineering Group, CATV Products Division, URO ELECTRONICS IND. CO., LTD., 5-27-10 Minami-Ohi, Shinagawa-ku, Tokyo 140-0013, Japan.

E-mail: nakajima-noboru@uro.co.jp able. In the case of high head and critical low flow rate micro hydropower resource, it requires very low specific speed turbines which are lower than conventional impulse turbine particularly the Pelton type, which works best at high head and low flow rate (known as lowest specific speed turbine).

The pressure in the water supply system (WSS) is normally much higher than required. There is a large amount of dissipated energy due to a high pressure differential at the inlet and outlet of water faucets. A simple calculation reveals, that each time we use a water faucet, 10 to $80 \mathrm{~W}$ of power is dissipated. A simple calculation for selecting an appropriate turbine within the water supply system can be used. For example: if an overall efficiency about $60 \%$, turbine is connected to a generator with a speed of $1000 \mathrm{~min}^{-1}$, for every maximum available power points of water faucets (for pressure $>0.10 \mathrm{Mpa}$ ), the specific speed $\left(n_{s}=n P^{1 / 2} / H^{5 / 4}\right)$ will be in the range of 2.2 to 4.8 and the average specific speed is about $3.7\left[\mathrm{~min}^{-1}, \mathrm{~m}\right.$, $\mathrm{kW}$ ]. For this specific speed, there is no suitable turbine type, because the impulse turbine has the specific speed range of 10 to $70^{(4)-(6)}$. To realize the present requirement of specific speed, we proposed a new turbine type, which is a Positive Displacement Turbine (PDT).

The objective of this study is two-fold: First, we want to study the characteristics of the WSS and estimate its micro hydropower potential for power generation at the 
water faucets. Secondly, we want to develop the new turbine which has very low specific speed, simple structure and high efficiency.

\section{Nomenclature}

$B:$ Height of rotor $[\mathrm{m}]$

$D$ : Diameter [m]

$f:$ Frequency $[\mathrm{Hz}]$

$H:$ Head [m]

$L O N$ : Number of the lobe order

$n:$ Revolution speed $\left[\mathrm{min}^{-1}\right]$

$n_{s}:$ Specific speed $\left[\mathrm{min}^{-1}, \mathrm{~m}, \mathrm{~kW}\right]$

$N_{u}:$ Unit speed $\left[\mathrm{min}^{-1}\right]$

$p:$ Pressure $[\mathrm{MPa}]$

$P$ : Power [W]

$P_{u}:$ Unit power $[\mathrm{W}]$

$Q:$ Flow rate $\left[\mathrm{m}^{3} / \mathrm{s}\right]$

$T:$ Mechanical toque $[\mathrm{Nm}]$

$V_{d}:$ Volumetric displacement $\left[\mathrm{m}^{3} / \mathrm{rad}\right]$

Greek symbols

$\eta$ : Efficiency

$\rho:$ Density $\left[\mathrm{kg} / \mathrm{m}^{3}\right]$

$\omega:$ Angular velocity [rad/s]

Subscripts
$l:$ Losses or leakage
$o:$ Output
th: Theoretical

\section{Water Supply System \& Its Micro Hydropower Potential}

The normal flow rate range at the outlet of the faucets in houses, offices etc. is about four to $10 \mathrm{~L} / \mathrm{min}$ which is the interesting range for this study, as it is shown in Figs. 1 and 2 the range between two vertical dashed lines.

To make water flow from the faucets requires only a small differential pressure between the inlet and outlet. However, to ensure water flows to all users, the utilities always supply a higher water pressure than is required.

In this study, different sources of water supply systems (residential houses, office buildings, etc.) in the city of Yokohama were investigated. The results are shown in Figs. 1 and 2. Figure 1 shows the pressure and flow relationship of the water faucets tested. The maximum pressure and flow rate are in the range of $0.1-0.54 \mathrm{MPa}$ and $11-36 \mathrm{~L} / \mathrm{min}$, respectively, which are much higher than the normal requirement. All of the houses use water from the water supply utilities while most of the high-rise buildings require a booster system or pump to deliver the water to the top of building, where it can be distributed to each floor.

We can see in Fig. 1 that not all the curves are parallel to each other as they should be. This may be because of the different pipe diameters. From the data in Fig. 1, the estimation of the available micro hydropower poten-

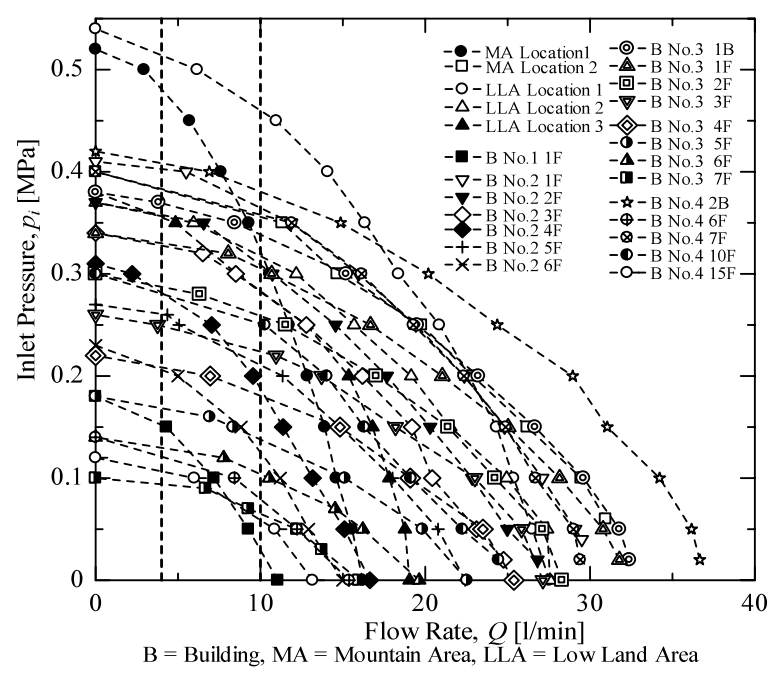

Fig. 1 Inlet pressure and flow rate relationship of water faucet of water supply systems

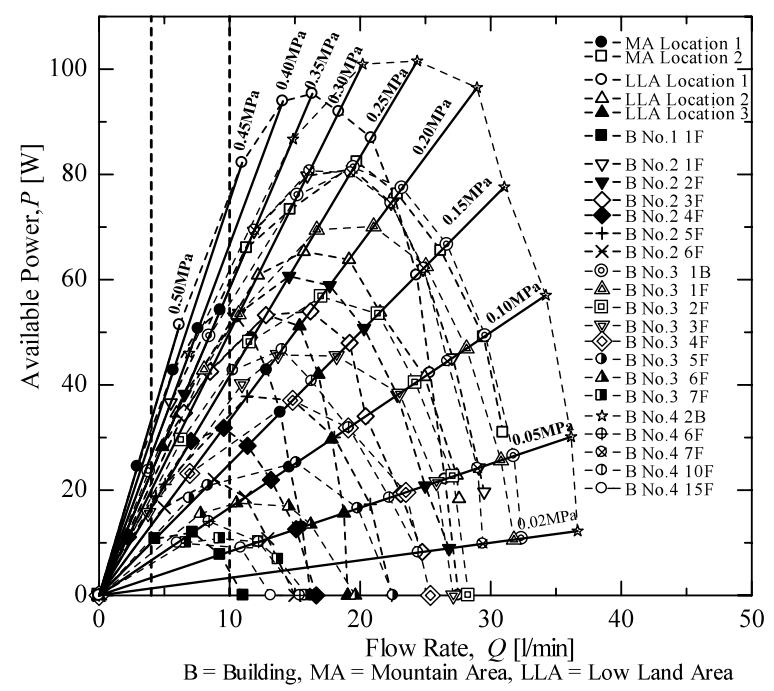

Fig. 2 Available power, flow rate and pressure relationship of WSS in Yokohama

tial of the water supply system at the end used valves can be computed by $P=\rho g Q H$. The result is shown in Fig. 2 . The maximum available hydropower varies between $10 \mathrm{~W}$ to $100 \mathrm{~W}$.

\section{Test Apparatus and Method}

\subsection{Testing facilities}

Figure 3 shows the schematic view of the testing system. The designed water supply system has the ability to test the turbine in the range of $0-60 \mathrm{~L} / \mathrm{min}$ and $0-$ $0.7 \mathrm{MPa}$ of flow rate and pressure, respectively. Water is pumped from the water tank (1) and is supplied to the system by multi-stage pump (2). The effective head $H$ is varied by adjusting the rotational speed of the pump and adjusting the pressure control valve (12). The amount of water flow to the turbine is controlled by the valve (6). While the valve (11) is used for controlling the discharge 


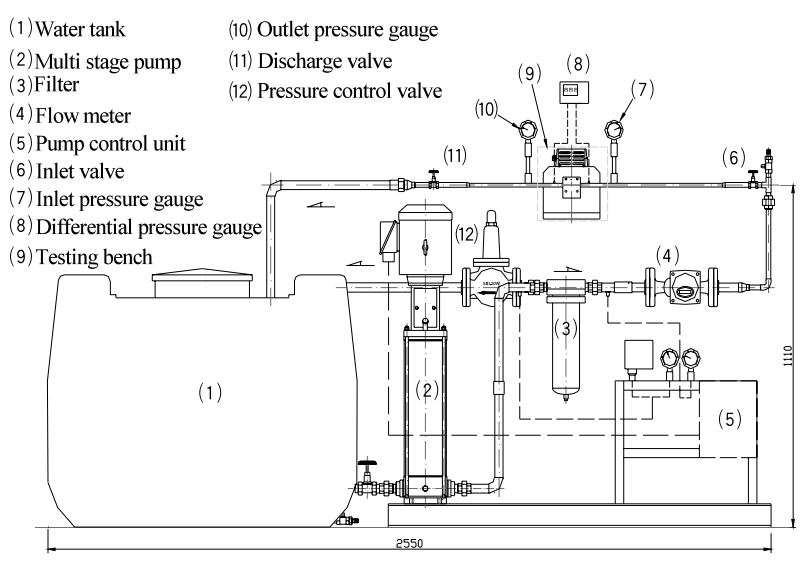

Fig. 3 Schematic view of testing system

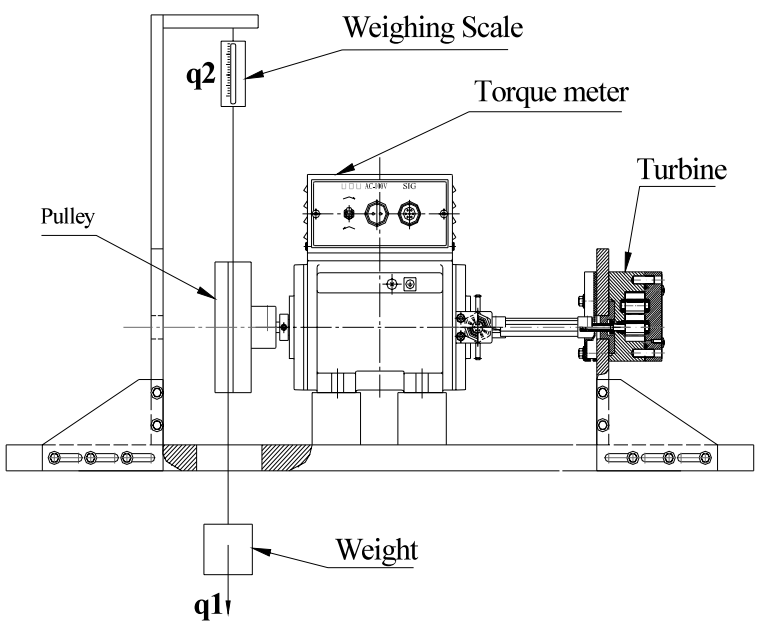

Fig. 4 Testing bench

pressure.

The turbine-testing bench (9) is designed for measuring the turbine performance, as shown in Fig. 4. The turbine shaft is connected to one end of the torque meter by a coupling and the other end of the torque meter is connected, either to an electric generator or mechanical load. The mechanical load can measure the torque of the turbine by applying the load to the turbine (called a weighing scale torque). The weighing scale torque meter gives a very accurate torque measurement when the generating heat from the friction between pulley and rope is fully cooled.

\subsection{Turbine design}

Figure 5 shows a positive displacement micro-hydro turbine design. A rotary three-lobe turbine was selected because of its simplicity. The fluid flows into the turbine's inlet port under pressure. Because pressure at the inlet port is greater than at outlet port, fluid can cause the rotors to rotate against the load torque. The whole view of the turbine is shown in Fig. 5 (a). The turbine consists of two rotors, two shafts, four bearings, casing, and cover. Bearings support both ends of the shafts with the three-lobe rotors located between bearings. This resists shaft deflection and contact between the rotors and casing wall. The rotors

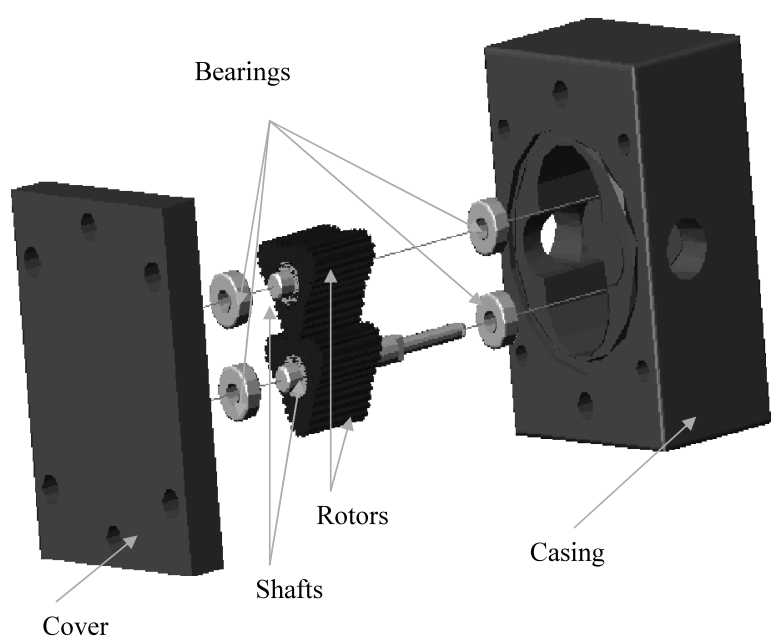

(a) Whole view of PDT

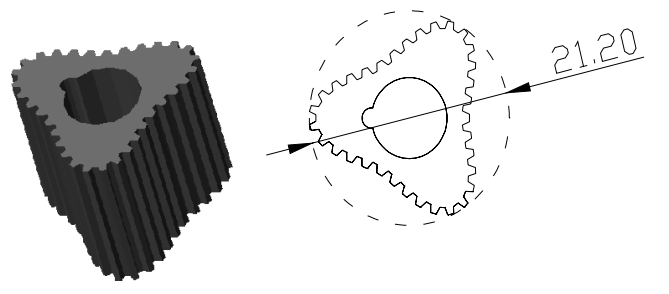

(b) Rotor profile

Fig. 5 Positive displacement turbine design

are made of hard plastic and have a diameter of $21.2 \mathrm{~mm}$ and height of $16.4 \mathrm{~mm}$. The rotors are tightly fixed with shafts by spring-pins. To improve the torque transmission between the two rotors, the rotors are designed to have a spur gear around the curve shape. The gear on each rotor has 33 teeth, see Fig. 5 (b).

In ideal PDT, there is no leakage from inlet to outlet ports and the rotational speed of the turbine is directly proportional to the flow rate. Thus, the main interest of the study is to determine the efficiency of the PDT and the influence of the leakage on efficiency.

\subsection{Experimental method}

Generally, hydraulic turbines are designed to operate at a certain values of revolution speed, discharge, effective head, power and efficiency ${ }^{(7)}$. However, micro water faucet turbine operates under the wide range of effective head but narrow range of flow rate. Therefore, it is necessary to test the performance characteristic of the turbine under the constant flow rate.

Tests are performed by maintaining a constant flow rate and the speed $(n)$ is varied by changing the load on the turbine. For each value of $n$, the torque and differential pressure across the turbine are measured. Similar tests are performed at different flow rates. The value of input power $P$ and output power $P_{o}$ can be computed by $P=\rho g Q H$ and $P_{o}=T \omega$, respectively. These powers determine the overall efficiency of the turbine by using $\eta=P_{o} / P$.

The performance curves of the turbine are normally 
plotted in the form of efficiency against revolution speed, power against revolution speed, flow rate against revolution speed etc. It is common practice in turbo-type machine to use the unit speed and unit power which are derived from the similarity law to reveal the performance characteristics of turbines $^{(7)}$.

Unit speed and unit power are expressed as follows:

$$
\begin{aligned}
N_{u} & =\frac{n D}{H^{1 / 2}} \\
P_{u} & =\frac{P_{o}}{D^{2} H^{3 / 2}} \quad \text { (for conventional turbine) } \\
P_{u} & =\frac{P_{o}}{(D B) H^{3 / 2}} \quad \text { (for new turbine (PDT)) }
\end{aligned}
$$

In order to compare the performance characteristics of the new turbine with a conventional turbine, a small impulse turbine was tested. Conventional turbine is referred to a small Turgo impulse type, which has developed and used for automatic water faucets for several years now. This turbine has two nozzles and each of them has a jet area of $3.14 \mathrm{~mm}^{2}$. The turbine runner has a diameter of $22 \mathrm{~mm}$, which is nearly equal to the PDT's diameter, with 14 buckets.

Both the Turgo impulse turbine and new turbine were tested using a constant flow rate test-method. As it was mentioned earlier, the water turbines are design to work at certain values of revolution speed, discharge and effective head. However, turbines are often required to work at the conditions far from the designing point. Therefore, it is important to examine the behavior of the turbines under the various conditions.

The test on the Turgo impulse turbine was conducted for constant flow rate and supply head up to $7 \mathrm{~L} / \mathrm{min}$ and $25 \mathrm{~m}$ respectively. The maximum head and flow rate for the PDT test were $70 \mathrm{~m}$ and $14 \mathrm{~L} / \mathrm{min}$, respectively. The revolution speeds of the Turgo impulse turbine and PDT are in the range of $0-10000 \mathrm{~min}^{-1}$ and $0-2800 \mathrm{~min}^{-1}$, respectively.

Due to the pressure pulsations in the positive displacement turbine, the effective head is calculated by the time average of the inlet and outlet pressure.

\section{Experimental Results (Turbine Performances)}

\subsection{Positive displacement turbine versus Turgo impulse turbine}

Figures 6 and 7 show the comparison of performance characteristics of the Turgo impulse turbine with the new turbine. It is clear that the new turbine has much better efficiency and much higher output power than the Turgo impulse turbine when they are operated under the same conditions. The maximum efficiency of the Turgo impulse turbine is $25 \%$ when it is operated at a flow rate and head in the range of $4-5 \mathrm{~L} / \mathrm{min}$ and $8-12 \mathrm{~m}$, respectively. Moreover, the specific speed is 9.5. In contrast, PDT has the maximum efficiency of about $62 \%$ and the specific speed

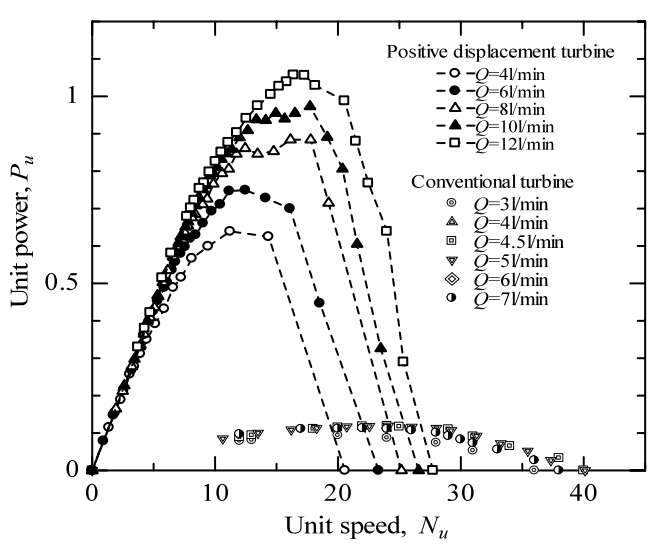

Fig. 6 Variation of unit power with unit speed

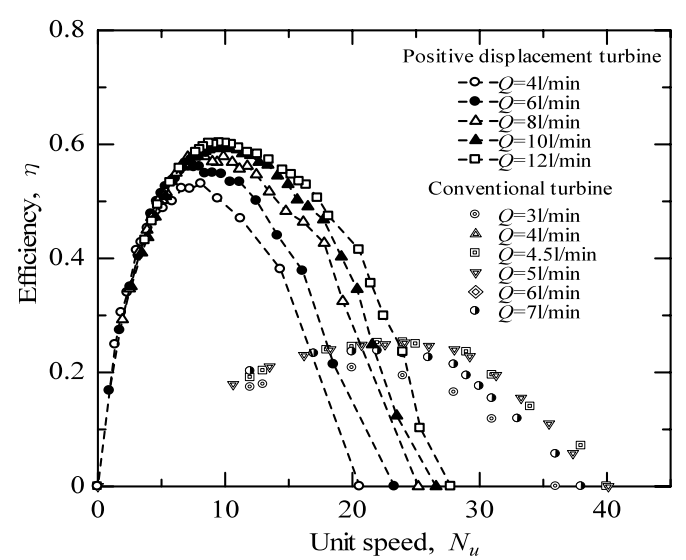

Fig. 7 Efficiencies of PDT and CT at different flow rates

is about 5 within the test range. There are two reasons why this small Turgo impulse turbine has such low efficiency: first, is the size. Normally the efficiency of the larger size impulse turbines is about $90 \%$, but it becomes much lower in the smaller size. Second, unlike the usual impulse turbines, the runner of the small impulse turbine rotates fully immersed in water, therefore the efficiency drops drastically.

In addition, the efficiency of the PDT increases when it is operated at higher flow rates. The optimum efficiencies of the PDT and Turgo turbines appear at different unit speeds. This is primarily because the revolution speed of the Turgo turbine is much higher than PDT (about six times at the same flow rate).

The results also show that the highest efficiency of the PDT is obtained when it operates at a flow rate of $12 \mathrm{~L} / \mathrm{min}$, which is 2 times higher than average flow rate of water faucets. Because the flow rate is proportional to the displacement volume of the rotors, therefore, the new turbine size should be smaller of current size for use at the water faucets, and/or be bigger size for using in other piping systems which have higher flow rate range.

\subsection{Performance improvement by modification of the turbine side clearances}

The new turbine is designed to have both side and 


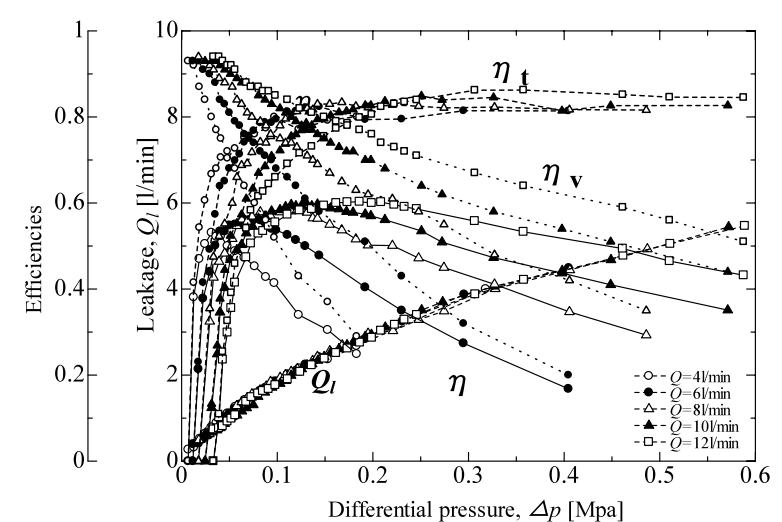

(a) Side clearance of $60 \mu \mathrm{m}$

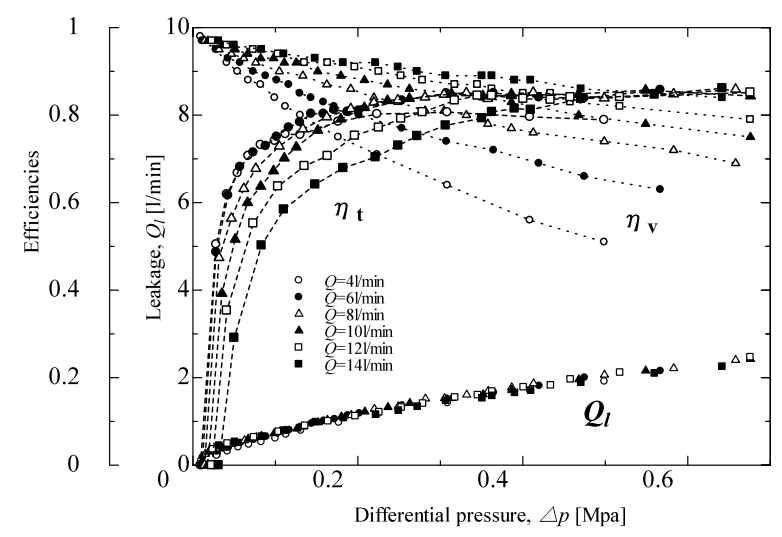

(b) Side clearance of $10 \mu \mathrm{m}$

Fig. 8 Variation of efficiency and leakage with effective head

tip clearances of $60 \mu \mathrm{m}$. The tip and side clearances are clearances between the casing wall and the lobe rotors and the clearance between the sides of the rotors and the side plates, respectively.

The variation of efficiencies and leakage through the clearances of two cases side clearances with effective head are shown in Fig. 8. The amount of leakage $\left(Q_{l}\right)$ was estimated by $Q_{l}=Q-Q_{t h}$, where $Q$ is the discharge volume measuring at the outlet of the turbine and $Q_{t h}$ is the theoretical displacement volume delivered by rotors per unit time $\left(Q_{t h}=V_{d}^{*} \omega\right)$. From Fig. $8(\mathrm{a})$, we can see that the high efficiency ( $\eta \geq 95 \%$ of $\eta_{\max }$ ) operating range of PDT (of $60 \mu \mathrm{m}$ side clearance) is narrow and the efficiency rapidly decreases with increasing of head. This is because of the amount of water leakage through the clearances between the rotating and stationary parts of turbine. In positive displacement turbine, the revolution speed is proportional to $Q_{t h}$. Figure 8 (a) shows that, increasing of the effective head results more leakage (and reduce $Q_{t h}$, at the same discharge $Q$ ). For example, at $6 \mathrm{~L} / \mathrm{min}$ constant discharge $Q$, when turbine operated at $40 \mathrm{~m}$ of head about $2 / 3$ of the discharge water comes from $Q_{l}$. This directly reduces the revolution speed of the turbine and consequently affects the volumetric efficiency $\left(\eta_{V}=Q_{t h} / Q\right)$ and overall efficiency $\left(\eta=\eta_{t} * \eta_{v}\right)$ of the turbine. The side clearance

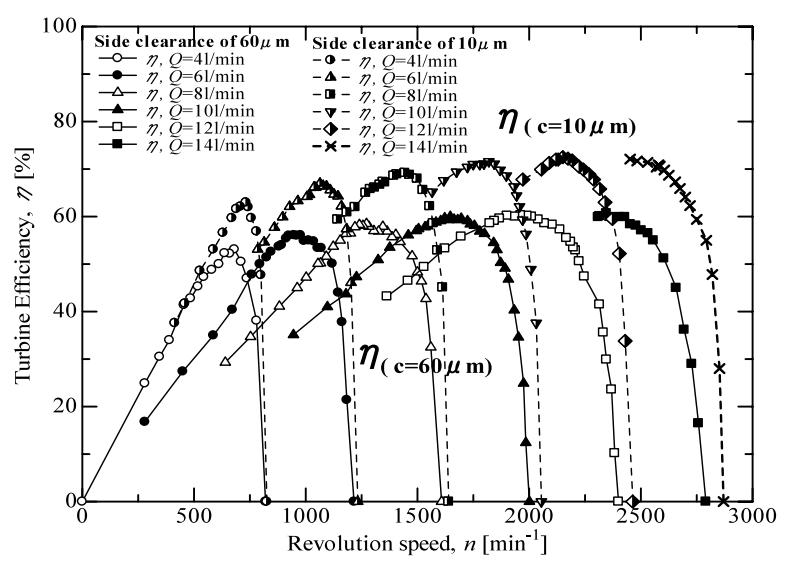

Fig. 9 Variation of efficiency with revolution speed

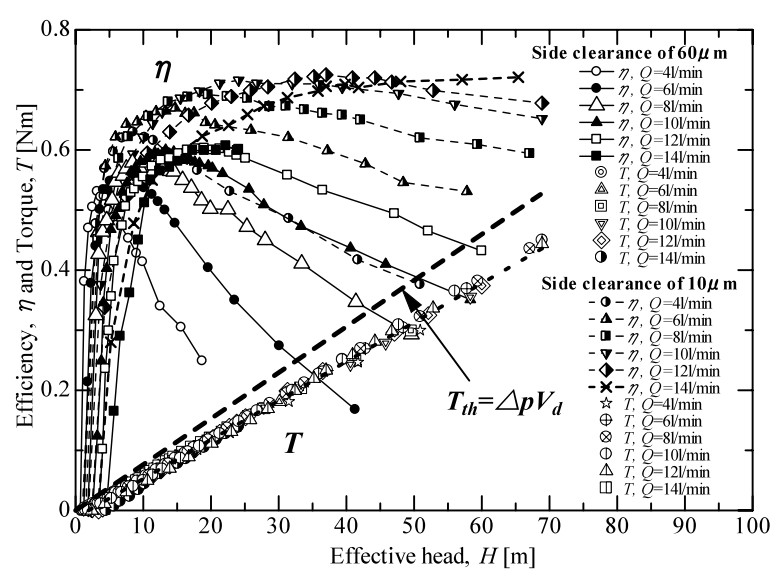

Fig. 10 Variation of efficiency and torque with effective head

was decreased from $60 \mu \mathrm{m}$ to $10 \mu \mathrm{m}$ to improve the efficiency of the new turbine.

The comparison of performance characteristics of PDT between before and after modifications of the side clearances is shown in Figs. 8-10. From these results, it is found that the leakage is significantly reduced (about 2.5 times) and the maximum overall efficiencies have been improved by 10 to 12 percent depending on the operating conditions. Figure 10 shows that PDT, with the side clearance of $10 \mu \mathrm{m}$, operates with the highest efficiency of about $72 \%$ at the flow rate of $12 \mathrm{~L} / \mathrm{min}$ and $37 \mathrm{~m}$ of head. Moreover, unlike the PDT with a big side clearance, the PDT with smaller side clearance can work under the high efficiency ( $\eta \geq 95 \%$ of $\eta_{\max }$ ) over much wider range of operating conditions. For example, at the flow rate of $12 \mathrm{~L} / \mathrm{min}$, the PDT with side clearance of $60 \mu \mathrm{m}$ can operate with high efficiency in the range of 10 to $25 \mathrm{~m}$ of head. In contrast, at the same flow rate, the PDT with $10 \mu \mathrm{m}$ can operate under higher efficiency in a much wider range, between 20 to $70 \mathrm{~m}$.

In the positive displacement machine, a theoretical torque is a function of differential pressure $(p)$ and volumetric displacement ${ }^{(8)}\left(V_{d}=Q_{t h} / \omega\right)$, which can be computed by $T_{t h}=p V_{d}$. The torque losses $\left(T_{l}\right)$ is composed 
of two major torque losses in PDT: first, the torque proportional to the turbine speed, because torque is required to shear the fluid in the small tip clearance in relative motion and second, torque required to overcome all the friction such as seal friction, side disks, bearings, and so on. The actual torque $\left(T_{a}\right)$ delivered to the load is computed by $T_{a}=T_{t h}-T_{l}=p V_{d}-T_{l}$. The torque efficiency is calculated by $\eta_{t}=T_{a} / T_{t h}$. From Fig. 8 (a) and (b) the torque efficiency of small side clearance is decreased noticeably in the range of low pressure region. This may be caused by the increasing of the viscous torque of the side ends of the rotors. However, the improvement of the volumetric efficiency of the turbine with small side clearance is much higher than the torque efficiency reduction. Thus the overall efficiency is increased significantly, see Figs. 9 and 10. As the torque losses are small and change a little, the turbine's torque is only dependent on the pressure, is shown in Fig. 10 that the torque of PDT is directly proportional to the pressure (effective head) and is independent of the flow rate.

The measured torques and mechanical output power in the large side clearance case and small side clearance case are compared in Figs. 11 and 12. We can see from Fig. 11 that, the revolution speeds of the PDT with bigger side clearance is reduced significantly with the increase of

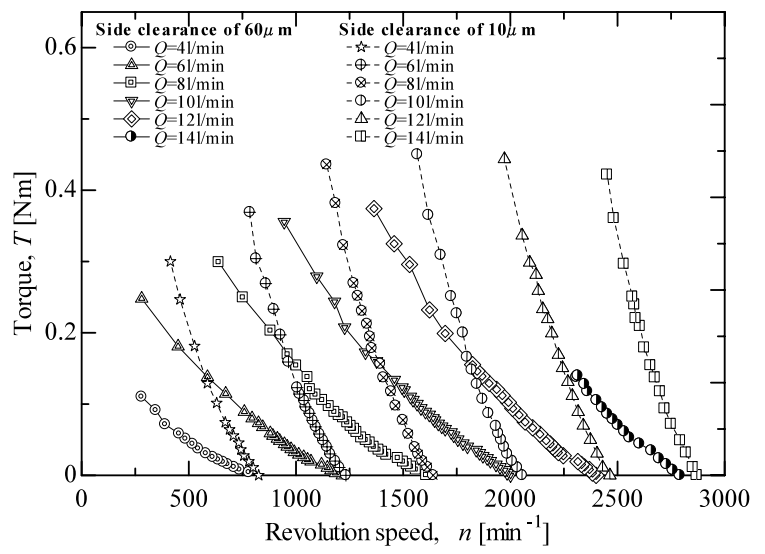

Fig. 11 Torque and revolution speed relationship

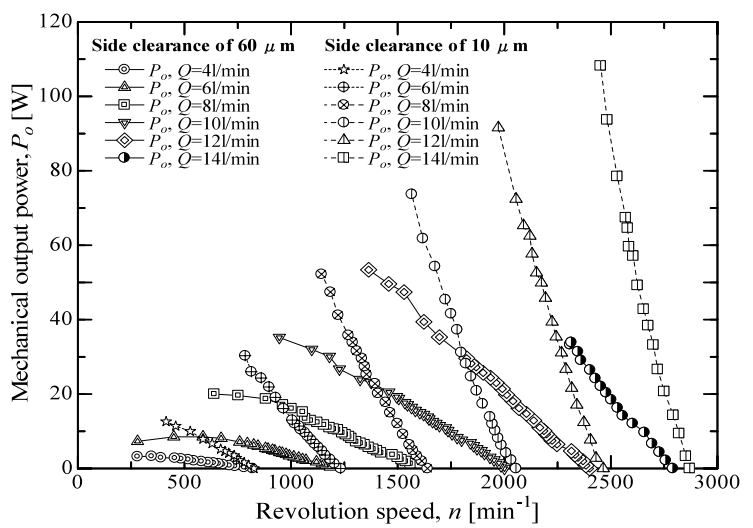

Fig. 12 Output power and revolution speed relationship torque (head). In contrast, relatively small changes of the revolution speeds are recognized in the small side clearance case. At the same torques, the revolution speed of PDT with a small side clearance is much higher than PDT with a large side clearance. Figure 12 reveals that PDT with a smaller side clearance can obtain much higher output power and consequently higher efficiency than PDT with a large side clearance at the same head and flow rate, particularly when turbine operates at high head.

\subsection{Pressure pulsations}

In the PDT, the intermittent flow of the fluid through the inlet and outlet of the turbine generates pressure pulsations. Pressure pulsations have two important characteristics: frequency and amplitude. The comparison of frequency and amplitude of pressure pulsations are shown in Fig. 13. The results measured at $60 \mathrm{~mm}$ far from the inlet and outlet ports of the turbine. The pressure pulsations measured at $200 \mathrm{~mm}$, upstream and downstream sides of the turbine, they did not show any significant differences in value.

Figure 13 (a) shows the amplitude of the pressure

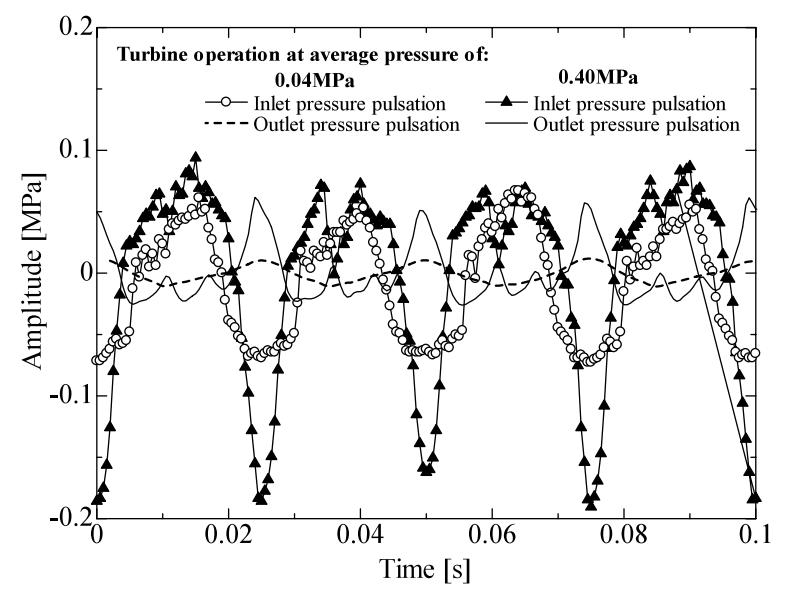

(a) Constant speed, $n=800 \mathrm{~min}^{-1}$

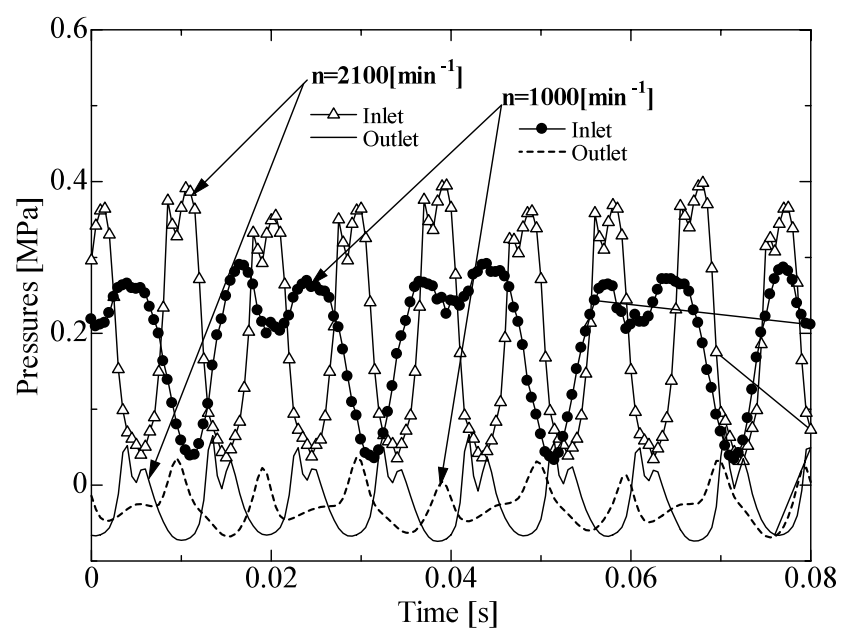

(b) Constant pressure (head), $p=0.2 \mathrm{MPa}$

Fig. 13 Pressure pulsations 
pulsations of the turbine operating at different heads but same speed. Figure 13 (b) shows the pressure pulsations when the turbine works at the same head but different speeds. The frequency of the pressure pulsation is equal to $f=n *(L O N) / 30$. From Fig. 13 (a), we can see that when the turbine works at higher head, the magnitude of pressure pulsations of both inlet and outlet of the turbine increase. From Fig. 13(b), the magnitudes of the pressure pulsations also increase when the turbine operates at higher speeds.

These pulsations are sometimes very severe and can cause damage to the piping or other components in a hydraulic system. To eliminate and/or minimize pressure pulsations can be achieved by judicious use of acoustic filters and side branch accumulators ${ }^{(9)}$ or modification of the rotor shapes. In this study, small bladder pressure tanks were used. The pressure tank is $20 \mathrm{~mm}$ in diameter and $50 \mathrm{~mm}$ in height and charged by air (see Fig. 14(a)). A rubber sheet was used as the bladder in order to prevent the contact between fluid and charged gas. Figure 14 (b) shows the comparison of the pressure pulsations between turbines operating with and without dampers. The results in Fig. 14 show that by installing only one damper close to

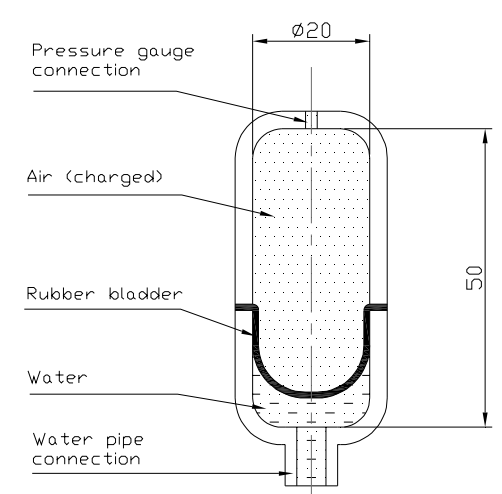

(a) Side-branch accumulator

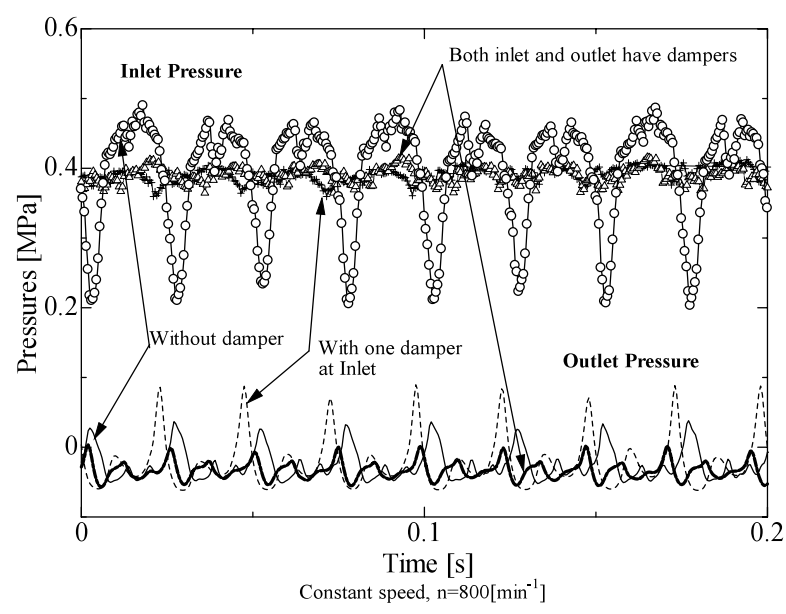

(b) Reduction of pressure pulsations

Fig. 14 Reduction of pressure pulsations by dampers the inlet port of the turbine, it makes the inlet pressure become nearly stable. However, the pulsation of outlet pressure is increased. Therefore, only $1 / 2$ of the differential pressure pulsation can be reduced. In contrast, when two dampers were installed at both the inlet and outlet of the turbine more than $3 / 4$ of the pressure pulsations were eliminated. Consequently, vibration and noise are reduced, resulting smoother operation.

\section{Conclusions}

From the results of this study the major conclusions are summarized as follows:

(1) A new positive displacement turbine was developed. The efficiency of new turbine is much higher than the small Turgo impulse turbine (about 2.9 times).

(2) The new turbine, with a smaller side clearance, has much higher efficiency than the turbine with bigger side clearance and it can sustain the high efficiency under the wider range of operation conditions.

(3) The maximum efficiency of the new turbine is $72 \%$ when it operates at $12 \mathrm{~L} / \mathrm{min}$ and $37 \mathrm{~m}$ of flow rate and head, respectively. To fit for the normal size of water faucets, the PDT size should be smaller than current size.

(4) The pressure pulsations of this turbine can be eliminated about $80 \%$ by using simple construction dampers.

( 5 ) The turbine torque of the PDT is proportional to the effective head and independent of the flow rate. The leakage is also depended on the effective head and nearly independent of the flow rate.

It is quite clear from the study that the positive displacement turbine is suitable for the micro-hydropower generation which requires very low specific speed much lower than impulse turbine specific speed. The new turbine is also applicable for extracting micro-hydropower at the valves of other piping systems.

\section{Acknowledgement}

The authors would like to express their sincere gratitude to TATSUNO Mechatronics Co., LTD. for proving the experiment apparatus. Grateful thanks to Dr. Kazunari Matsumoto for his continuous help during research study.

\section{References}

(1) European Renewable Energy Exchange, Small Hydropower Fact Sheet, http://www.earorex.com

( 2 ) Davis, S., Microhydro: Clean Power from Water, (2003), New Society Publishers, Canada.

( 3 ) Water Recycle Group, Electricity from Water with PowerPal, Micro and Mini Hydroelectric Generators, Canberra, Autralia.

( 4 ) Thake, J., The Micro-Hydro Pelton Turbine Manual, (2000), ITDG Publishing, London.

( 5 ) Harvey, A. and Brown, A., Priyantha Hettiarachi and Allen Inversin, Micro-Hydro Design Manual, (2005), ITDG Publishing. 
( 6 ) Barna, P.S., Fluid Mechanics for Engineerings, (1964), Butter Worths, London.

( 7 ) Nag, P.K., Power Plant Engineering, (2002), McGrawHill, Singapore.

( 8 ) Merritt, H.E., HYDRAULIC CONTROL SYSTEMS,
(1967), John Wiley \& Sons, Inc., New York.

(9) Karassik, I.J., Messina, J.P., Cooper, P. and Heald, C.C., PUMP HANDBOOK, (2001), McGraw-Hill, New York. 